\title{
Effect of Electrode Coatings in Wire Electrical Discharge Machining of Inconel-718
}

\author{
S.R.Dhale ${ }^{1}$, M. L. Kulkarni ${ }^{2}$ \\ ${ }^{1}$ Research scholar, Walchand Institute of Technology, Ashok Chowk, Solapur- 413006 \\ ${ }^{2}$ Professor, JSPM Narhe Technical Campus, Pune- 411041
}

\begin{abstract}
Wire electro-discharge machining (WEDM) has developed as extensively recognized non-traditional machining process for difficult-to-cut materials. In this paper, the behavior of Inconel-718, has been studied by varying electrode coating using WEDM, with respect to performance measures such as MRR and surface finish. All experiments were performed on Electronica Ultra cut wire EDM. The experiments were conducted by varying pulse on time, pulse off time, wire feed, wire tension, dielectric flush pressure. The experimental results confirm that, with coated wire, material removal rate and surface finish is better.
\end{abstract}

Keywords: WEDM, MRR, SR

\section{Introduction}

Nickel base super alloys are extensively used in high temperature applications such as gas turbines, electric power generation equipment, nuclear reactors and high temperature chemical vessels. Nickel based superalloys such as Inconel are widely used in aerospace engines to achieve weight reduction and increased thermal efficiency, nuclear, and chemical industries because of their excellent mechanical and chemical properties at elevated temperatures. It is estimated that Nickel-based superalloys compose over half of the materials that are used in the aerospace industry, in particular for the hot section of gas turbine engines for components such as turbine disk, blades, combustors, etc.[1] Inconel 718 is a precipitation-hardened nickelchromium alloy. It contains substantial levels of iron, molybdenum, and niobium and trace amounts of titanium and aluminium, possessing high strength and temperature-resistance combined together.[2] In the recent years, wire electrical discharge machining (WEDM) has become an important non-traditional machining process, widely used in the aerospace and automotive industry. The WEDM process has the ability to machine precise, complex and irregular shapes through difficult to machine electrically conductive components. [3] . It is a thermo-electrical process in which material is removed by generating a series of discrete sparks between electrode and work piece immersed in a liquid dielectric medium. These electrical discharges melt and vaporize diminutive amounts of the work material, which are then ejected and flushed away by the dielectric. Since, the work piece and the electrode do not have mechanical contact, conductive material regardless of their hardness and toughness can be machined by WEDM. It consume a continuously travelling wire electrode made of thin brass, copper or coated wire of diameter 0.05 to $0.3 \mathrm{~mm}$, which is capable to achieve very small corner radii and competency to machine precise, complex and irregular shape with high degree of accuracy and fine surface finish.[4] In general, the cutting performance of the WEDM procedure depends on a combination of electrical, mechanical, physical, and geometrical properties of the wire electrode. For high-speed cutting and highprecision machining, any wire electrode should have key physical properties, like high electrical conductivity, tensile strength, elongation, melting point, and straightness.

Two types of wire electrodes are commonly used plain Brass and coated wire. Plain Brass was the successor to Copper wire and is still the most commonly used wire today. Brass, which is an alloy of Copper and Zinc, delivers a powerful combination of low cost, reasonable conductivity, high tensile strength, and improved flushability. Brass wire electrodes are extensively used on account of their ability to generate stable discharge, but their electrical conductivity is low.

Zinc coated Brass wires was one of the first attempts to present more Zinc to the wire's cutting surface. The addition of conductive alloying elements to the core surface of wire electrodes controls clarification and heat release. This wire consists of a thin (approximately 5 micron) zinc coating over a core which is one of the standard EDM brass alloys. Adding zinc to the wire electrode helps control electrical discharge properties, subsequently enhancing machining performance. Several inventors have focused their efforts toward enhancing wire electrode performance by controlling the above methods. [5]

Deepak Rajendra Unune et at[6], considered the effect of various electrode materials like copper, copper-tungsten, and tungsten on material removal rate and electrode wear rate in micro-EDM drilling of Inconel-718. It was found that Copper electrodes results in highest MRR at all values of gap voltage and capacitance followed by copper tungsten and tungsten electrodes. 
J.Prohaszka et al [7], reported the requirement of the materials used for WEDM electrodes that will lead to improvement of WEDM performance. It was revealed that machinability during WEDM was improved significantly with the proper combination of mechanical, physical and geometrical properties of the electrode. Electrode materials should have high melting and evaporation temperature. Coating may increase considerably the cutting efficiency.

Farnaz Nourbakhsha, K. P. Rajurkar,[8] et al, used Taguchi method to investigate the effect high speed brass wire and zinc-coated wire. The influence of zinc-coated brass wire on the performance of WEDM was compared with high speed brass. It was found that compared with high speed brass wire, zinc-coated brass wire results in higher cutting speed and smoother surface finish. Also, SEM photographs revealed that uncoated wire produces a surface finish with more cracks, craters and melted drops. Also high speed brass wire resistance against wire rupture in tough conditions, high pulse width and low time between two pulses, was much more than zinc coated wire since tensile strength of zinc coated wire was less than the high speed brass wire tensile strength. Chalisgaonkar and Jatinder Kumar[9] studied the effect of wire brass and zinc coated along with other parameters. The microstructure analysis of the work surface indicated that zinc coated wire produced overlapping thick layer of debris while uncoated wire produced more number of craters under similar higher pulse discharge energy conditions.[10]

Arvind Kumar Yadav et al[11] made a comparative study of zinc coated and bare electrode in EDM. It was concluded that coated tool electrode have significant effect on the material removal rate, tool wear and surface finish. The copper tool without coating gives poor performance in machining. It gives high surface roughness value and maximum tool wear rate as compare to coated tool with same machining parameters. The coated tool takes less machining time as compare to naked copper tool at the same machining parameters.

From literature review it is clear that very few considered the effect of electrode coating on performance measures. As most of the research in WEDM is limited only with variation of process parameters and influence on the response variables such as material removal rate, kerf width and surface finish. And for nickel based alloys research constrained to feasibility and aftermath of machining. In this paper combined study of WEDM of Inconel-718, is presented considering the effect of electrode coating.

\section{A. Experimental Set up}

\section{Experimentation}

In the present study all the experiments were carried out on a ELECTRONICA machine tool make Ultra Cut wire cut EDM.(Fig. 1.)

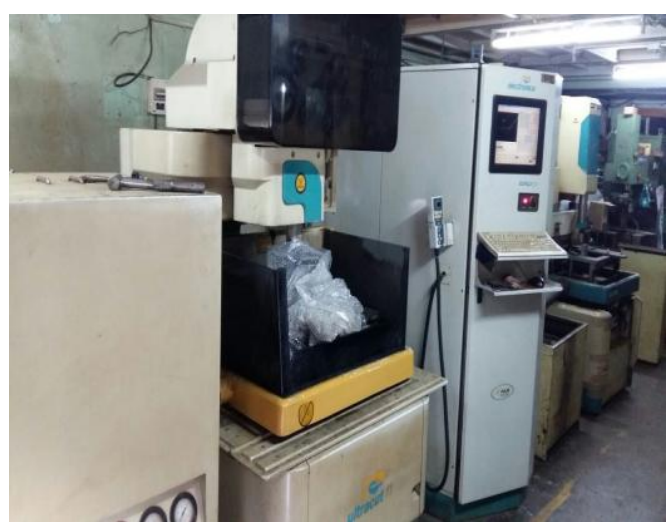

Fig. 1 Electronica Ultra cut WEDM set up

\section{B. Experiment materials}

\section{1) Work Material :}

Inconel-718, (150x150x8) $\mathrm{mm}$ is used for experimentation. The chemical composition as received from recognized certified lab for material testing is shown in Table 1.

Table 1: Chemical Composition Of Inconel-718

\begin{tabular}{|l|l|l|l|}
\hline Element & Wt \% & Element & Wt \% \\
\hline Nickel & 54 & Silicon & 0.20 \\
\hline Chromium & 16.5 & Iron & 19.6 \\
\hline Molybdenum & 3.14 & Copper & 0.0001 \\
\hline Cobalt & 0.26 & Carbon & 0.0380 \\
\hline Titanium & 0.89 & Sulfur & 0.014 \\
\hline Manganese & 0.11 & Phosphorus & 0.0030 \\
\hline
\end{tabular}




\section{2) Electrode Materials:}

Plain Brass and Zinc coated wires are used in this investigation. The approximate values of their properties received from recognized lab are as tabulated in the Table. 2

Table 2: Wire Electrode Material Properties

\begin{tabular}{|l|l|l|}
\hline Wire Name & Plain Brass & Zinc Coated \\
\hline Material & Plain Brass & Zinc coated Brass \\
\hline Diameter & $0.25 \mathrm{~mm}$ & $0.25 \mathrm{~mm}$ \\
\hline Tensile strength & $500 \mathrm{~N} / \mathrm{mm}^{2}$ & $500 \mathrm{~N} / \mathrm{mm}^{2}$ \\
\hline Composition & $\mathrm{Cu} 59.88 \%$ & $\mathrm{Cu} 59.92 \%$ \\
& $\mathrm{Zn} 40.03 \%$ & $\mathrm{Zn} 39.96 \%$ \\
\hline
\end{tabular}

\section{Design of Experiments based on Taguchi method.}

Taguchi's approach has been built on traditional concepts of Design of Experiments (DOE), such as full factorial, fractional factorial design and orthogonal arrays based on signal -to-noise ratio, robust design and parameter and tolerance designs. DOE is a powerful statistical technique introduced by R.A. Fisher in England in 1920s to study the effect of multiple variables simultaneously [Philips (1989)]. Since, the research work concentrates on the experimental work, the number of experiments is to be conducted, the effect of the individual parameters on the Wire-EDM, either independently or combinedly have to be studied. Therefore, the well known Taguchi technique is chosen and adopted in the present research work.

In order to reduce the total number of experiments "Sir Ronald Fisher" has developed the solution: "Orthogonal Arrays". The orthogonal array is a distillation mechanism by which the engineers can select the experimental process. The array allows the researcher / engineer to vary multiple variables at one time and obtain the effects such that set of variables has an average and the dispersion. Taguchi employs the design of experiments using specially constructed table, known as "Orthogonal Arrays" (OA) to treat the design process, such that the quality is build into the product during the product design stage. Orthogonal Arrays are the special set of Latin squares, constructed by Taguchi to layout the product design experiments.[12] A typical Orthogonal Array selected 'L18' and the levels of process parameters are given Table 3. A mixed level design which gives the flexibility to choose different levels for every process parameters. As for wire, we can have only two levels of plain brass and zinc coated. However with other parameters, we can keep three levels each.

Table 3 Process Parameter Levels L18 Oa

\begin{tabular}{|l|l|l|l|l|}
\hline Parameters & levels & \multicolumn{3}{l|}{ Values } \\
\hline Wire Material & 2 & \multicolumn{1}{l|}{ Brass } & \multicolumn{2}{l|}{ Zinc coated } \\
\hline Pulse on & 3 & 110 & 112 & 115 \\
\hline Pulse off & 3 & 49 & 50 & 51 \\
\hline wire feed & 3 & 3 & 4 & 5 \\
\hline wire tension & 3 & 2 & 3 & 4 \\
\hline flushing pressure & 3 & 4 & 5 & 6 \\
\hline
\end{tabular}

The levels of pulse on, pulse off, are taken with reference to the literature. Flushing pressure level is as per the machine setting of low, medium and high. Current employed in the complete machining process has to be kept constant, also we cant change the dielectric fluid used. The commonly used dielectric fluid is demonized water; however we had used plain tap water as the dielectric fluid. Servo voltage is also maintained at constant level. The values of constant parameters are tabulated in Table. 4.

Table 4 Fixed Parameters

\begin{tabular}{|l|l|}
\hline Shape and size of workpiece & $150 \times 150 \times 8 \mathrm{~mm}$ \\
\hline Dielectric fluid & Tap water \\
\hline conductivity of dielectric fluid & 15 \\
\hline Servo voltage & 20 \\
\hline current & 12 \\
\hline
\end{tabular}

\section{Results and discussion}

The experimental results are collected for Material removal rate (M.R.R.) and for surface finish. Performance measures were statistically analyzed using analysis of variance and signal-to-noise ratio to evaluate the effects of selected variables and to determine the influence of electrode coating on response variables.

\section{A. Analysis of variance (ANOVA:}

In the present study all the designs, plots and analysis have been carried out using Minitab17 software. The performance measures were statistically analyzed using analysis of variance (ANOVA). The analysis of variance was performed at $95 \%$ confidence level. The associated P-value for the model is lower than 0.05 (i.e. 
$=0.05$ ), indicating that the model is statistically significant. It is used to establish statistically significant process parameter. Statistically, Larger F-value indicates that the variation of the process parameter makes a big change on the performance characteristics. According N.Tosun[13] higher value of F-ratio shows that any small variation of the process parameter can make a significant influence on the performance characteristics. The results of ANOVA for the performance measure are presented in Table 5-6.

Table 5 Anova For M.R.R

\begin{tabular}{|l|l|l|l|l|l|}
\hline Control Factors & DF & Adj SS & Adj MS & F- Val & P-Val \\
\hline Wire Material & 1 & 0.029 & 0.029 & 2.4 & 0.172 \\
\hline Pulse On & 2 & 0.84527 & 0.42264 & 34.98 & 0.000 \\
\hline Pulse Off & 2 & 0.00856 & 0.00428 & 0.35 & 0.716 \\
\hline Wire Feed & 2 & 0.00852 & 0.00426 & 0.35 & 0.716 \\
\hline Wire Tension & 2 & 0.0263 & 0.01315 & 1.09 & 0.395 \\
\hline Flushing Pressure & 2 & 0.03627 & 0.01813 & 1.50 & 0.296 \\
\hline Error & 6 & 0.0725 & 0.012083 & & \\
\hline Total & 17 & 1.02642 & & & \\
\hline S & R-sq & R-sq(adj) & R-sq(pred) \\
\hline 0.109925 & $92.94 \%$ & $79.99 \%$ & $36.43 \%$ & \\
\hline
\end{tabular}

According to ANOVA for M.R.R. it is observed that with this process parameter configuration, Pulse On is the most significant process parameter with F-value of 34.98 , and P-Val of $0.00<0.05$, also the R-sq and $\mathrm{R}$-sq(adj) values are within limits. And important to note is out of other all parameters wire material is next significant parameter with F-value of 2.4. Indicating the effect of coating.

Table 6 Anova For Surface Finish

\begin{tabular}{|l|l|l|l|l|l|}
\hline Control Factors & DF & Adj SS & Adj MS & F- Val & P-Val \\
\hline Wire Material & 1 & 0.002450 & 0.002450 & 23.21 & 0.003 \\
\hline Pulse On & 2 & 0.287433 & 0.143717 & 1361.53 & 0.000 \\
\hline Pulse Off & 2 & 0.000933 & 0.000467 & 4.42 & 0.066 \\
\hline Wire Feed & 2 & 0.000133 & 0.000067 & 0.63 & 0.564 \\
\hline Wire Tension & 2 & 0.000033 & 0.000017 & 0.16 & 0.857 \\
\hline Flushing Pressure & 2 & 0.000033 & 0.000017 & 0.16 & 0.857 \\
\hline Error & 6 & 0.000633 & 0.000106 & & \\
\hline Total & 17 & 0.291650 & & & \\
\hline S & \multicolumn{7}{|l|}{ R-sq } & R-sq(adj) & R-sq(pred) \\
\hline 0.010274 & $99.78 \%$ & $99.98 \%$ & $98.05 \%$ & \\
\hline
\end{tabular}

According to ANOVA for surface finish, it is observed that with this process parameter configuration, Pulse On is the most significant process parameter with F-value of 1361.53 , and. and important to note is out of other all parameters wire material is second most significant parameter with F-value of 23.21

\section{B. Signal-to noise $(\mathrm{S} / \mathrm{N})$ ratio:}

Taguchi separates the factors that influence the response characteristic into two main groups. Control factors and noise factors. Control factors are the one that are controllable process variables whereas noise factors are uncontrollable factors that cause significant variation in the response characteristic. Taguchi accounts for these noise factors by first defining a loss function which implies that a loss is resulted as soon as there is variation of response from the desired target value. Based on the response characteristics of interest three scenarios are common i.e. nominal the best, smaller the better where target value is zero and larger the better where target value is infinity.[14]

The higher value of $\mathrm{S} / \mathrm{N}$ ratio thus corresponds to the better performance irrespective of the category of the performance characteristics and therefore the process could be optimized without removing the cause of variation but making it robust against the noise factors.

In the work herein smaller the better is employed for surface finish since smaller value is desirable whereas larger the better is adopted for material removal rate(MRR) as shown in the equations.

For smaller the better.

$$
\frac{S}{N}=-10 \log \left(\frac{1}{n}\right) \sum_{i=1}^{n} y^{2}
$$

For larger the better

$$
\frac{S}{N}=-10 \log \left(\frac{1}{n}\right) \sum_{i=1}^{n}\left(\frac{1}{y^{2}}\right)
$$


Where $\mathrm{n}=$ no of replications, And $\quad \mathrm{Y}=$ observed response variable value. Signal to noise $(\mathrm{S} / \mathrm{N})$ ratios were calculated to find out the optimum levels of the parameters. Table 7 shows the value of $\mathrm{S} / \mathrm{N}$ ratio of each performance characteristics. The level corresponds to higher $\mathrm{S} / \mathrm{N}$ value is the optimum level. The peak value of SN ratio helps to identify significant parameters and analyse their effects on MRR and surface finish.

Table 7 S/N Ratios For All Experiments

\begin{tabular}{|l|l|l|l|l|l|}
\hline Expt No & M.R.R. (dB) & Surface finish (dB) & Expt No & M.R.R. (dB) & Surface finish (dB) \\
\hline 1 & 3.33130 & -8.62728 & 10 & 3.27188 & -8.56270 \\
\hline 2 & 3.69230 & -8.56270 & 11 & 3.90710 & -8.46492 \\
\hline 3 & 4.44866 & -8.59505 & 12 & 4.86041 & -8.49763 \\
\hline 4 & 5.19529 & -8.78665 & 13 & 4.40435 & -8.65939 \\
\hline 5 & 5.07636 & -8.72325 & 14 & 5.08642 & -8.62728 \\
\hline 6 & 3.96833 & -8.75501 & 15 & 5.59948 & -8.65939 \\
\hline 7 & 6.46613 & -9.48433 & 16 & 6.82439 & -9.45513 \\
\hline 8 & 5.93972 & -9.45513 & 17 & 6.77535 & -9.42583 \\
\hline 9 & 5.94528 & -9.42583 & 18 & 6.59688 & -9.39644 \\
\hline
\end{tabular}

The results of SN ratios are graphically represented with main effects plot for material removal rate and surface finish Figure 2-3. For machining of Inconel-718 by zinc coated and plain brass wire it gives the nature and trend of variation. It shows that with zinc coated wire MRR is considerably increased. Also with the increase pulse on and pulse off there is increase in MRR. However for wire feed and wire tension there is no considerable change in the material removal rate. [8]. Flushing pressure is considered here as one of the process parameter showed increase in MRR with increase in its value from 4 to 6 . All the plots and analysis is made with the help of stastical software minitab 17.

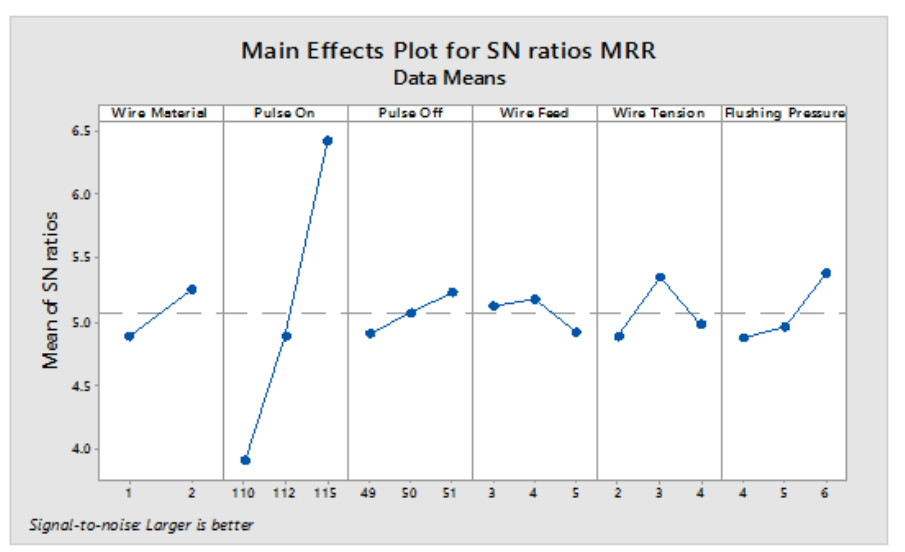

Fig. 2 Main Effect Plot for S/N for M.R.R.

However from the main effects plot for surface finish figure 3, it is found that, surface finish is lower with brass wire than coated wire, and also lower with flushing pressure. However it increases with pulse on time and wire feed and wire tension are not significant in controlling the kerf width.

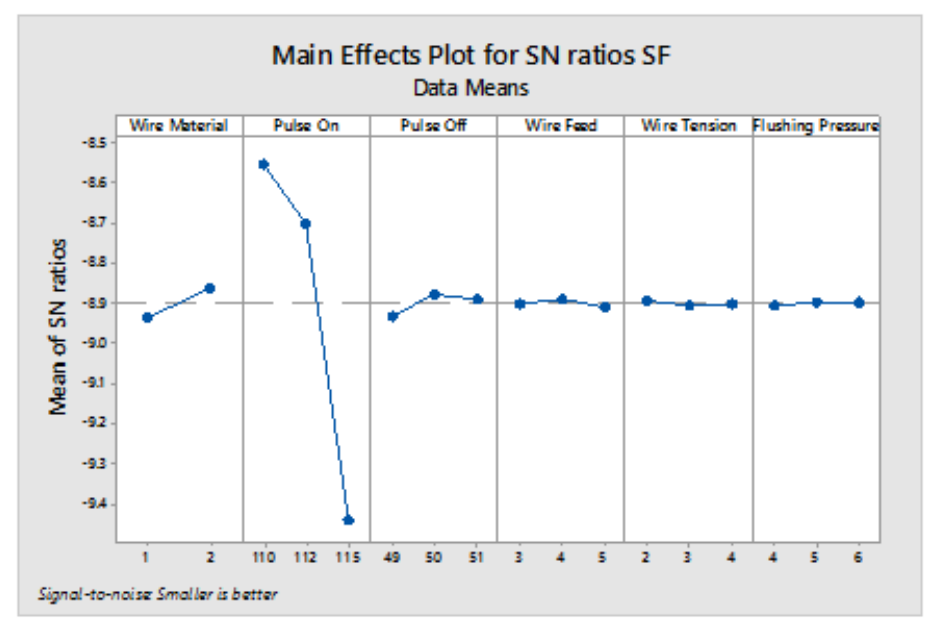

Fig. 3 Main Effect Plot for S/N for Surface finish 
It can be observed that the electrode coating plays significant role in MRR. The dielectric breakdown in WEDM action is dependent on both work piece as well as electrode material. But the electrode material has more noticeable effect on breakdown of dielectric since it plays first role in breakdown of dielectric. Also the electric and thermal properties of electrode material are off important consideration. Being an electro thermal process, the electrical and thermal conductivity and the melting points of both the electrode and workpeice material attributes major role in WEDM performance.[2]

As the coated wire contains a thin $(5 \mu \mathrm{m})$ layer of zinc on the brass core, the low melting point zinc particles vaporize quickly following spark ignition and contribute to increased gap conductivity and therefore, enable use of higher working gap between the electrodes, which results in better flushing characteristics. Additionally, the vaporization of zinc coating helps to maintain lower temperature of wire core, which permits use of more intensive pulse power and results in increased cutting speed. The enhancement in the machining speed contributed to the higher surface roughness observed during the trim cut operation with zinc coated wire[10]

It is observed that with zinc coated wire material removal rate is higher as compared to plain brass wire. Direct dependence of the cutting efficiency upon both melting temperature and work function, was revealed, the cutting speed was observed to increase with the increase of the melting temperature. [7]

The relationship of the MRR to the melting temperature of the cathodic tool can be also explained taking into account the concept of the energy distribution

in the gap, the greater the melting temperature of the tool electrode the smaller the penetration of the melting isothermal inside the material, and, therefore, the larger the amount of energy available for the erosion of the workpiece.

The range of MRR with zinc coated wire is higher than brass wire. In fact, the addition of zinc to brass wire leads to reduction in wire melting point. The low melting temperature of wire improves the spark formation and decrease dielectric ionization time. Thus, the MRR increases.

But due the effect of zinc coating surface finish is considerably increased. The zinc-coated brass wire can produce smoother surface in comparison with brass. The existence of zinc in coated brass wire provides higher tensile strength for wire. The wire with high tensile strength is a good heat resistance in high temperature and maintains straight under vibration and tension. Also, the uniform zinc layer on coated wire provides good discharge characteristics. A finer discharge can be created with good discharge characteristics and higher tensile strength. As a result, the quality of work piece surface will improve.

\section{Conclusions}

In this study, the influence of zinc-coated brass wire on the performance of WEDM is compared with brass. Also, the effect of process parameters on the process performance was determined by performing experiments under different machining conditions. Based on the experimental results and analysis, the following conclusions are put forth.

1. Experiments results of WEDM of Inconel-718, indicate primarily there is considerable influence of wire material, brass and zinc coated.

2. Pulse on time and wire material has significant effect on material removal rate.

3. Compared with brass wire, zinc-coated brass wire results in higher material removal rate.

4. Zinc coated wire give better surface finish as compared to brass wire.

5. Flushing pressure is also the next significant parameter. Higher flushing pressure values give higher M.R.R.

\section{References}

[1]. L. Li, Y. B. Guo, X. T. Wei, and W. Li, "Surface integrity characteristics in wire-EDM of inconel 718 at different discharge energy," Procedia CIRP, vol. 6, pp. 220-225, 2013.

[2]. F. Klocke, D. Welling, A. Klink, D. Veselovac, "Evaluation of advanced Wire-EDM capabilities for the manufacture of fir tree slots in inconel 718," Procedia CIRP, vol. 14, no. 1, pp. 430-435, 2014.

[3]. M. S. Hewidy, T. a. El-Taweel, and M. F. El-Safty, "Modelling the machining parameters of wire electrical discharge machining of Inconel 601 using RSM,” J. Mater. Process. Technol., vol. 169, no. 2, pp. 328-336, 2005.

[4]. A. Alias, B. Abdullah, and N. M. Abbas, "WEDM: Influence of machine feed rate in machining Titanium Ti-6Al-4V using brass wire and constant current (4A)," Procedia Eng., vol. 41, no. Iris, pp. 1812-1817, 2012.

[5]. I. Maher, A. A. D. Sarhan, and M. Hamdi, "Review of improvements in wire electrode properties for longer working time and utilization in wire EDM machining," Int. J. Adv. Manuf. Technol., vol. 76, no. 1-4, pp. 329-351, 2014.

[6]. D. R. Unune, "Performance Investigations of Different Electrode Materials in Micro-EDM Drilling of Inconel-718."

[7]. J. Prohaszka, A. . Mamalis, and N. . Vaxevanidis, "The effect of electrode material on machinability in wire electro-discharge machining," J. Mater. Process. Technol., vol. 69, no. 1-3, pp. 233-237, 1997.

[8]. F. Nourbakhsh, K. P. Rajurkar, A. P. Malshe, and J. Cao, "Wire Electro-Discharge Machining of Titanium Alloy," Procedia CIRP, vol. 5, pp. 13-18, 2013.

[9]. R. Chalisgaonkar and J. Kumar, "Optimization of WEDM process of pure titanium with multiple performance characteristics using Taguchi’s DOE approach and utility concept,” Front. Mech. Eng., vol. 8, no. 2, pp. 201-214, 2013. 
[10]. R. Chalisgaonkar and J. Kumar, "Investigation of the machining parameters and integrity of the work and wire surfaces after finish cut WEDM of commercially pure titanium,” J. Brazilian Soc. Mech. Sci. Eng., vol. 38, no. 3, pp. 883-911, 2016.

[11]. A. K. Yadav and S. K. S. Yadav, "Experimental study of Zinc coated and bare electrode machining of Ni-alloy for EDM- A comparative study."

[12]. C. B. Reddy, G. J. Reddy, and C. E. Reddy, "Growth of Electrical Discharge Machining and Its Applications - A Review," Int. J. Eng. Res. Dev., vol. 4, no. 12, pp. 13-22, 2012.

[13]. N. Tosun, C. Cogun, and H. Pihtili, "The Effect of Cutting Parameters on Wire Crater Sizes in Wire EDM," Int. J. Adv. Manuf. Technol., vol. 21, no. 10-11, pp. 857-865, 2003.

[14]. A. Ikram, N. A. Mufti, M. Q. Saleem, and A. R. Khan, "Parametric optimization for surface roughness, kerf and MRR in wire electrical discharge machining (WEDM) using Taguchi design of experiment," J. Mech. Sci. Technol., vol. 27, no. 7, pp. 2133$2141,2013$. 